\title{
APRENDIZAGEM HISTÓRICA E CULTURA HISTÓRICA: CONTRIBUTOS PARA INVESTIGAÇÕES SOBRE O LUGAR DA INTERSUBJETIVIDADE NA FORMAÇÃO HISTÓRICA
}

\author{
HISTORICAL LEARNING AND HISTORICAL CULTURE: CONTRIBUTIONS TO \\ RESEARCH ON THE ROLE OF INTERSUBJECTIVITY IN THE HISTORICAL \\ FORMATION
}

Rafael Reinaldo Freitas ${ }^{1}$

\begin{abstract}
RESUMO: No presente texto, a proposta é analisar os conceitos de cultura histórica, consciência histórica e sua complexa relação quando pensando a aprendizagem histórica, além de apontar suas contribuições para investigações que busquem entender o envolvimento do sujeito aprendiz com artefatos culturais portadores de discurso histórico. Tais reflexões são pautadas no âmbito das pesquisas sobre ensino e aprendizagem da história a partir dos estudos da Educação Histórica sob a conceptualização da aprendizagem histórica extraídas do filosofo da história Jörn Rüsen. Neste sentido, a partir das contribuições sobre a intersubjetividade e verdade trazida por Marcelo Fronza e da problematização do lugar do sentimento e da razão conforme Bodo V. Borries, a didática da história alemã surge como campo de investigação que possibilita profícuos debates na problematização do envolvimento sujeito, artefatos culturais e conhecimento histórico no entrelaço entre consciência histórica e cultura histórica.
\end{abstract}

Palavras-chave: Aprendizagem histórica. Cultura histórica. Intersubjetividade

\begin{abstract}
In this paper, the purpose is to analyze the concepts of historical culture, historical consciousness and the complex relationship when considering the historical learning, while pointing out their contributions to research that aims to understand the involvement of the student with cultural artifacts bearers of historical discourse. These reflections are based on the scope of investigation on teaching and learning of history from the studies of History Education in the conceptualization of historical learning taken from the philosopher of history Jörn Rüsen. In this sense, from the contributions of intersubjectivity and truth brought by Marcelo Fronza and issue of place of feeling and reason as Bodo V. Borries, the teaching of German history emerges as a field of research that enables fruitful discussions on the difficulties of commitment subject, cultural artifacts and historical knowledge in Webbing between historical consciousness and historical culture.
\end{abstract}

Keywords: Historical Learning. Historical Culture. Intersubjectivity

\footnotetext{
1 Mestrando em História pela Universidade Federal de Mato Grosso. Bolsista CAPES. Integra o Grupo Pesquisador Educação Histórica: Didática da história, consciência histórica e narrativas visuais (GPEDUH/UFMT/CNPq).
} 


\section{Introdução}

$\mathrm{Na}$ convicção da formação histórica como consequência de diferentes instâncias da vida, este artigo se propõe a analisar os conceitos de cultura histórica e consciência histórica no intuito de entender o lugar e a importância de diferentes artefatos de cultura portadores de narrativa histórica de constituição de sentido. Insere-se no conjunto de pesquisas as quais tomam como parâmetro investigativo a cognição histórica situada (SCHMIDT, 2009) e se pautam na epistemologia da história para a delimitação e interpretações de questões que envolvam o estudo das ideias históricas de sujeitos, em diálogo com a teoria da consciência histórica (RÜSEN 2010a).

Ao pensar a aprendizagem histórica em uma centralidade naquilo que se aprende, ao invés naquilo que se deveria aprender, observa-se a manifestação de diferentes fontes, posicionamentos e identidades históricas que trazem consigo contribuições de filmes, quadrinhos, músicas e jogos eletrônicos, por exemplo.

A consciência histórica está exposta a diversas intervenções intencionais e involuntárias, conforme a vivência em sociedade. Sabores estéticos, a rememoração dos feitos coletivos, a tradição que envolve o moderno nas diferentes formas de narrar e entender os percalços da vida humana ao longo do tempo, seja institucionalmente transmitida, como na escola, ou em contextos fora dela, o discurso histórico aparece em diferentes linguagens constituindo orientação temporal futura.

Diante disso surge a seguinte pergunta: qual a relação entre aprendizagem histórica e os meios de comunicação de massa, e como manter uma emancipação do sujeito diante de tanta informação? Pensando no debate qualificador de aprendizagem, onde a racionalidade científica precisa ser mantida, é importante que entendamos o lugar da verdade nestas interferências e sua relação no processo de subjetivação do saber histórico.

Uma possibilidade de encararmos tal problema é através da intersubjetividade como reduto de aparecimento e permanências de narrativas históricas materializadas a partir da cultura histórica vigente. Isto exposto o 
objetivo central deste artigo é apresentar como pesquisadores do campo da educação histórica e da didática da história tem pensado a subjetivação do conhecimento histórico tomando contribuições de diferentes linguagens, na preocupação de evidenciar a aprendizagem histórica como processo resultante do sentimental e do racional, ou ainda, como mobilizações das diferentes dimensões da cultura histórica e diálogo com a consciência histórica.

No primeiro momento, apresentaremos brevemente o surgimento da didática da história a partir da experiência alemã, sua função e delimitação como campo de investigação da consciência histórica conforme trazido por Rafael Saddi (2014). No segundo momento tomamos auxilio das pesquisas de Marcelo Fronza (2012) e Bodo V. Borries (2016) para esclarecer o diálogo entre consciência histórica (individuo) e cultura histórica (totalidade) no processo de aprendizagem histórica.

\section{Didática da história: razões para o fazer da pesquisa histórica}

A Didática da História é uma resposta ao desafio de renovação da razoabilidade social para a pesquisa historiográfica, ao se verificar uma crise de legitimidade diagnosticada na incapacidade de responder às carências de orientação da sociedade alemã pós-guerra, perdendo em importância social (SADDI 2014, p. 136).

Rafael Saddi (2014, p. 143) entende essa crise como consequência da incoerência entre as narrativas históricas e as carências de orientação na Alemanha pós-segunda guerra. A guerra exaltou a diferença geracional, abalando as convicções coletivas. Os jovens tinham a necessidade de conhecer e debater a história recente da Alemanha - contexto do nazismo - "mas a ciência história e o ensino de história não haviam acompanhado esta transformação. Ao contrário, eles permaneciam sob os mesmos moldes em que foram formulados nos tempos de Bismark".

Desta maneira, a História respondia as necessidades exigidas durante a unificação alemã em 1871 - A história apoiava-se no princípio formativo em 
narrativas exemplares, (a história magistre vitae), afirmando-se como uma disciplina "investigativa tendo como norte o caráter exemplar onde os personagens e situações históricos investigados academicamente serviriam de exemplos de ação para a construção do estado-nação" (FRONZA 2014, p. 141).

Perdendo espaço para outras disciplinas, a exemplo da sociologia, somente na década de 1960, com mais ênfase na década de 1970, os historiadores alemães se debruçaram na renovação da história enquanto ciência, sua teoria e método. Neste contexto surge um grupo de historiadores que buscou firmar a relação entre o conhecimento histórico e os interesses da sociedade, e a partir da teoria da consciência histórica, demonstrar a relevância da história para a vida humana.

Jörn Rüsen é um dos intelectuais que abordam a teoria da consciência histórica, pelo caráter idiossincrático da formação histórica. Afastando-se de autores - alguns que compartilhou publicações e estudos, como Klaus Bergman - Rüsen defendia que "a história não era algo pronto e acabado que deveria ser meramente recebida pelo sujeito, mas uma reconstrução narrativa do próprio homem" (SADDI, 2014, p. 134).

O filósofo alemão, portanto, busca entender as carências de orientação, o processo de subjetivação e motivação, a partir da teoria da história, tendo como aporte teórico uma "Nova Didática da História" (RÜSEN, 2010a, 2010b). Rüsen propõe uma renovação no sentido de ensinar e aprender história superando certos conceitos já estabelecidos, afirmando que a formação histórica deve ter como meio e fim a atuação da consciência histórica.

Consciência Histórica pode ser sintetizada como o conjunto das "operações mentais com as quais os homens interpretam sua experiência da evolução temporal de seu mundo e de si mesmos, de forma tal que possam orientar, intencionalmente, sua vida prática no tempo"(RÜSEN, 2010a, p.57).

Neste sentido é negada a noção externa da didática da história, para com a ciência da história, que Ihe atribui apenas um caráter funcional, ou seja, afastando-se de uma didática enxergada como a operação de transformar o complexo conhecimento científico em uma forma tangível para o nível básico do ensino. 
Essa externalização e a funcionalização da didática são consequências dos esforços em tornar a Histórica em um campo especializado da ciência durante o século XIX, sobrelevando a técnica em detrimento da preocupação sobre formatação historiográfica e outros processos fundamentais na construção do conhecimento histórico como as carências de orientação oriundas da vida prática que geram as problemáticas para a Histórica (RUSEN, 2007).

Na tentativa de reverter essa situação o Jörn Rüsen irá defender que a didática é preocupação fundamental da práxis do historiador, quando se observa a estreita ligação da ciência histórica com a vida prática, portanto, o conhecimento histórico produzido não está isolado da sociedade, mas sim deve satisfazer às necessidades de orientação.

Sendo assim as pesquisas históricas são efetivadas de acordo com a demanda social e tem como função oferecer formas de orientação para o superávit de ação humana, tornando o sujeito capaz de tomar posicionamento face aos eventos cotidianos. Contudo o rigor do método decorrente da cientificização do pensamento histórico pode gerar um produto que impossibilite o desenvolvimento das competências da consciência histórica.

É nessa incapacidade que se faz necessário desenvolver uma disciplina que seja capaz de garantir esse objetivo primordial, não como um mero transportador de conteúdo verticalizado, mas uma disciplina com competências próprias, cuja reflexão esteja interligada a práxis do historiar.

Assim a didática da história, segundo Rüsen, deverá se ocupar com os processos com os quais se desenvolve o aprendizado histórico, ou dito de outra forma, a didática da educação histórica busca potencializar os elementos implícitos do conhecimento histórico, tornando-os explícitos na narrativa histórica para que se desenvolvam as três dimensões da consciência histórica através da aprendizagem histórica: experiência do passado, a interpretação destes fatos, e a orientação para a vida prática.

A Didática da História se configura em uma disciplina especializada em tratar do conhecimento histórico nos mais diversos setores sociais, que não o ambiente acadêmico. Ela deverá estudar e buscar caminhos de levar o produto da pesquisa histórica em diversas formas de raciocínio, sem limitar seu campo de 
atuação à escola, "isso inclui o papel da história e as representações nos meios de comunicação de massa; ela considera as possibilidades e limites das representações históricas visuais em museus e explora diversos campos." (RUSEN, 2010c, p. 32-33).

Aprender história para Jörn Rüsen (2010, p.43) deve ser entendido como "um processo mental de construção de sentido sobre a experiência do tempo através da narrativa histórica, na qual as competências para tal narrativa surgem e se desenvolvem" - experiência, interpretação, orientação e motivação. Experimentar, interpretar e orientar-se são unificados em forma de pensamento histórico através da narrativa (RÜSEN, 2010a), através dela a consciência histórica pode ser explicitada, e ganhar sofisticação através da constituição de sentido sobre a experiência do tempo. O aprendizado histórico permite ao sujeito, o trato com o saber histórico de forma consciente, possibilita a interpretação e a problematização deste saber, para finalmente utiliza-lo.

A aprendizagem histórica através da experiência alarga a possibilidade de orientação em um processo de percepção de contingência de mudança entre o passado e o presente. O passado é entendido e relativizado em constante comparação com o presente, incita o sujeito a reconhecer o "eu" dentre as modificações humanas ao longo do tempo. A possiblidade do encontro da identidade em meio às transformações faz com que a competência de encontrar significados mediante o reconhecimento de si e do outro ganhe forma de interpretação e de posicionamento crítico transformando o modelo de interpretação tradicional em exemplar, e os exemplares em genéticos.

Nesta perspectiva o ensino da história toma para si a função de tornar consciente o passado de forma que o sentido a ele empregado seja capaz de orientar e projetar a direção ao futuro. O processo de formação e aprendizagem histórica não foge da relação aplicada da Teoria da História com a forma e função da pesquisa histórica; ele deve satisfazer o interesse e a carência da vida prática.

A Didática da História, portanto, é a disciplina que expande a ciência da histórica nos aspectos formativos dos sujeitos, em menor ou maior maturidade, em diferentes graus de escolarização, e em diferentes espaços da vida cotidiana quando em perspectiva da cultura histórica entendida como: 
a manifestação da consciência histórica na sociedade em diversas formas e procedimentos. Inclui o trabalho cognitivo dos estudos históricos, bem como as atitudes da vida cotidiana voltadas para a compreensão do passado e a conceitualização histórica de nossa própria identidade; e não podemos nos esquecer dos museus, nem as apresentações do passado nas diversas mídias ou na literatura (RÜSEN, 2015a, p. 24).

Se a história científica deve observar, interpretar e responder às carências de orientação temporal, esta deve garantir o surgimento de um discurso semântico de simbolização, uma estratégia para que as narrativas de constituição de sentido atinjam a consciência histórica, e influencie a cultura histórica - de maneira a sustentar ou modificá-la. A cultura histórica pode ser estudada a partir das suas 5 dimensões separadas para fins de análise, contudo estão entrelaçadas.

Sumariamente (a) a dimensão estética expõem as diferentes linguagens e abordagens do saber histórico - cientificamente erigido ou não - trata-se de estruturas artísticas, manifestações artísticas elucidativas do passado humano em confluência com a orientação temporal; (b) a dimensão política é percebida na organização institucional, da operação da consciência histórica, a escola, o arquivo, o currículo para o ensino de história, enfim, a permanência de espaços de memória e esquecimento; (c) a dimensão cognitiva é o elemento axial entre a estética e a política, lembrando o processo de formação histórica - Como eleger aquilo que deve ser lembrado, e esquecido? Ou melhor, tendo em vista a formação histórica, como, o que e para quem pensar a experiência humana e oferecer narrativas para interpretação e orientação? (d) a dimensão moral é onde a experiência humana ganha interpretação permeada em critério de valores da vida prática; (e) a dimensão religiosa manifesta aquilo que há de mais subjetivo, cujo valor interpretativo possui característica transcendentais.

Existe um movimento inexorável entre a cultura histórica e a consciência histórica, ao passo que, o entrelaçamento entre as dimensões - estética, política e cognitiva - pode gerar, tanto manipulação ideológica ou mesmo relativismo ético e moral, quanto pode converter-se em propostas que comportem concepções de mundo no qual o respeito à dignidade humana, o acolhimento da 
diversidade e os princípios da liberdade e igualdade sejam plenamente vivenciados. (ALVES, 2011, p. 33; BONETE \& FREITAS, 2015).

E quando observado a constituição de sentido para o passado da humanidade concordo com Divardim \& Schmidt (2014, p.119):

A constituição de sentido, necessária para a vida em sociedade, não se faz sozinha nas consciências dos indivíduos em relação de ensino e aprendizagem histórica. É necessário, segundo Rüsen, ter claro que a constituição histórica de sentido é um processo de convergência que ocorre na Cultura Histórica, e que há que preencher com sentido e significado a construção da narrativa que envolve a experiência humana no tempo.

Nessa perspectiva há de se levar em consideração a importância dos meios de comunicação de massa, onde o saber histórico é trazido numa linguagem que estetiza o passado humano de maneira diferente tal qual na historiográfica onde a cientificidade da história é demarcada pela operação da pesquisa histórica, e de tal forma reivindicadora de verdade.

\section{Intersubjetividade, aprendizagem histórica em um trato estético e cognitivo}

Um dos meios de entender manifestações artísticas como o jogo eletrônico sem limitar-se a ideia de artefato somente de lazer - e assim confundida e interpretada (artificialmente) como constructo não cognitivo onde a política e arte, como fator de orientação temporal, são instrumentalizados e enviesados pela alienação - está no lugar do saber histórico na cultura histórica.

A problematização desta posição deve passar pela pergunta: é possível falar, no âmbito da cultura histórica, em verdade histórica que não transpasse a razão como verdade científica? Se levarmos em consideração que a "ciência histórica e o ensino de história são eles próprios parta da cultura histórica" (BORRIES, 2016, p. 19) ambos devem responder às carências estéticas 
(sensoriais e emocionais) e políticas (dominação e poder/ validação jurídica) (RÜSEN 2010c).

A partir da função da didática da história, e na observação da coerência comunicativa a qual sintetiza a relação entre a pesquisa histórica com seu público-alvo, é na forma de se dirigir ao seu receptor que o historiador buscará a forma mais eficaz de inserir a vida prática, que as narrativas de constituição de sentido deverão ser "mediadas como for", desde que apresente um discurso histórico (RÜSEN, 2010c, p. 28).

Rüsen entende discurso histórico como o tipo de discurso em que "subsiste o saber histórico, isto é, em que aparece como parte integrante da orientação existencial, constituindo um elemento essencial da relação social na vida humana prática" (RÜSEN, 2010c, p. 28-29). Neste sentido, e se tratando da formação histórica, buscar entender como os meios de comunicação em massa trata o saber histórico presente na cultura histórica, a atribuição de sentido e que tipo de orientação existencial tem se percebido nas narrativas do sujeito.

O que se quer defender é que dar ênfase ao processo cognitivo nas formatações do saber histórico é tão nocivo para a função de orientação temporal para a consciência histórica, quanto em situação reversa: há uma tendência, principalmente nas discussões normativas e pragmáticas, da instrumentalização da razão pela política, percebido no rapto da verdade em nome de um projeto social muitas vezes agressivos e excludentes (estado-nação, identidade nacional, cultivo de tradição). Bem como na ineficiência semântica, que em nome da cientificidade, procura hierarquizar ou desqualificar a plasticidade - talvez, aí esteja, o medo dos profissionais de histórias presos "a tese de que a estética, no âmbito do pensamento histórico, só tem uma função legítima: a de 'transpor' ou 'intermediar' conteúdos cognitivos para formas esteticamente agradáveis" (RÜSEN, 2010c, p. 126-127).

É importante mencionar que Jörn Rüsen (2010, p. 29-29) adverte que, para a utilidade da percepção, ou ainda, para experimentar o passado humano, o saber histórico, ao ganhar forma de apresentação, não pode se abster daquilo que chamou de "coerência estética". A estética é entendida como a estratégia na qual o historiador cativará os sujeitos pela apresentação histórica. A 
comunicação simbólica tem como obrigação persuadir e influenciar de forma imediata o sujeito, apelando para o convencimento da percepção sensível.

Todavia, se é no fascínio estético que a empatia e a alteridade no tempo toma gosto, a ênfase na autonomia da estética em detrimento do cognitivo e político não contempla a função da formação histórica por entender que a identidade histórica calcada no sentimento subtrai a possibilidade de uma reflexão científica ocasionando a perda da orientação política necessária no processo de autodeterminação.

Por assim dizer, as formas de apresentação do saber histórico se desprendem da experiência de vida dos sujeitos em peso desarticulador das carências da vida prática corrompendo as estruturas orientadoras. "História Viva" não se refere exclusivamente ao realismo dado pela forma ou emoção evocada pela arte ou historiografia, mas viva em subjetividades e carências próprias no agir e sofrer humano pois, no ato intersubjetivo, revela-se a disputa interpretativa da experiência cuja motivação ao consenso só é possível mediante equilíbrio político e cognitivo.

No entanto, como já sabido, existe uma presença de meios de comunicação que fazem uso do discurso histórico que não tem como compromisso - nem são obrigados a tê-lo - a reinvindicação da verdade resultante da pesquisa histórica, ou por pareceres de sujeitos especializados em "História". Há nesse meandro, do surgimento à permanência de narrativas de constituição de sentido que trazem causalidades, temporalidade, narrativa e contextualização em um nível pré e pós críticas às fontes, cujo parâmetro normativo não se referencia na pesquisa histórica científica, e ainda assim oferece orientação e instigam a ação para o futuro.

Este debate não tem como objetivo colocar de maneira cerceada a função da história enquanto ciência, seus métodos e a formatação historiográfica, mas sim demonstrar as diferentes formas de aparecimento e subjetivação do conhecimento histórico.

Ainda sobre as dimensões da cultura histórica, Jörn Rüsen (2010c, p.131 - 132) sustenta o pensamento da não alienação do sujeito, seja pela cognição, política e também pela estética afirmando que somente na formação histórica a 
racionalidade mobiliza a consciência histórica de maneira a se depreender das alienações acima descritas, afirmando que "deve-se deixar espaço à faculdade representativa de lidar livremente com a experiência do passado" e conclui:

Essa liberdade deve estar relacionada às coerções das ambições políticas de poder e ao rigor racional da memória histórica. Dessa maneira, amplia-se o livre manejo das experiências históricas e das interpretações que orientam o agir. A estética filosófica sempre teve razão essencial da liberdade humana. A arte confere à elaboração da memória pela consciência histórica um potencial de sentido que pertence à vivacidade de toda cultura histórica (RÜSEN, 2010c, p.131 - 132).

Nessa direção Bodo V. Borries (2016) apresenta empiricamente como se dá o confronto entre as narrativas históricas de constituição de sentido cientificamente erigidas, e as narrativas históricas de constituição de sentido dos meios de comunicação de massa (cientificamente construídas, ou não). Conforme apontado, o jogo eletrônico, os quadrinhos, a música, cinema, enfim, linguagens que fogem ao debate em torno da historiografia, interferem na formação da consciência histórica das jovens estudantes, que articulado com o ensino e a aprendizagem histórica, os reflexos singulares ou em coletivos é operacionalizada pelas dimensões ética moral e religiosa.

Na subjetivação do conhecimento histórico interpretado, utilizado como fator orientador para contribuição na formação da identidade histórica, o indivíduo através do ato comunicativo efetua sua participação na cultura histórica tomando posição na disputa de poder, finalmente interfere e sofre interferência na forma a qual a experiência humana é narrada com perspectiva para ação futura - Intersubjetividade.

V. Borries afirma que pensar a formação histórica focada somente na sala de aula, e no ensino de história, como atesta suas pesquisas realizadas no espaço de experiência alemão, é incorrer na desilusão do trabalho "sem resultados". E contra isso é necessário pensar a formação histórica como contributos de várias instâncias sociais, dentre elas, as emoções relacionadas ao passado humano, auferindo que na disposição intelectual de se trabalhar com a história não se encerra com o cognitivo, e, portanto, atesta: 
O fato de que nesse caso estão em jogo apenas processos cognitivos é muitas vezes assumido tacitamente, mas é uma grande e perigosa ilusão. A história sempre tem a ver também com motivação e emoção, estética (prazer na formatação) e moral (aplicação de parâmetros éticos). Sobretudo não é possível separá-la nitidamente de imaginação e fantasia, e ela é influênciada também por tendências instintivas insconscientes (projeção, transferência, deslocamento, compulsão à repetição) (V. BORRIES, 2016, p. 19)

A guisa dessa discussão, Marcelo Fronza (2012) deteve-se em analisar a forma a qual jovens estudantes auferem verdade histórica no processo de aprendizagem partindo da história em quadrinho como linguagem problematizada. Para este pesquisador, a verdade histórica nos quadrinhos para estes jovens está vinculada à ideia de intersubjetividade, e somente por ela é possível entender como as estudantes tomam o conhecimento para si quando leem tais histórias em quadrinhos.

O aspecto intersubjetivo nesse processo indica a formação histórica como resultante de várias forças da esfera cultural, desta forma deve-se ter em mente que, primeiramente "a escola é o espaço da experiência social com o conhecimento em que a cultura se manifesta, incluindo aí a cultura juvenil e seus respectivos artefatos da cultura histórica, tais como a história em quadrinhos" (FRONZA, 2014 p. 195).

Outra importante contribuição de Fronza é a constatação dos artefatos culturais possibilitam a interpretação mediante aspectos incutidos na vida prática dos sujeitos suscitando a importância estética na percepção da experiência humana, ainda que tensionado com a ficção, o quadrinho - e por que não dizer os jogos eletrônicos fazendo as devidas ressalvas no tocante à narrativa mobilizam as dimensões da consciência histórica e transmitem significados e geram sentido para orientação temporal.

A intersubjetividade é elemento articulador da verdade histórica, e sua pertinência e permanência das narrativas ficcionais no processo de internalização do conhecimento histórico e de formação de identidade destes jovens ao subjetivar conceitos históricos. Desta forma Marcelo Fronza (2012, p. 39) 
entende que estes jovens participam da mesma estrutura de sentimento (WILIAMS, 2003) onde estão presentes aspectos éticos valores morais, estéticos e políticos no ato de alteridade e percepção da ação humana no tempo, entendimento do fluxo temporal.

A significação histórica atende a sua própria historicidade e lógicas mutáveis e aufere de sua pesquisa "os jovens estudantes de ensino médio, quando confrontados com duas histórias em quadrinhos de caráter didático, construíram argumentações baseadas em procedimentos mentais claramente influenciados pelo lugar social".

Bodo Von Borries (2016, p. 42) corrobora com tal conclusão ao entender:

Como as interpretações históricas e a consciência histórica são aprendidos pela socialização, os jovens vão ser claramente associados a essas mudanças. Muitas vezes a geração que está crescendo vai virar para uma versão alternativa, irá promover ideias opostas e, portanto, irá acelerar os movimentos sociais. Esta é uma estrutura típica do conflito geracional na história.

Tal indicativo está de acordo, tendo em vista o debate realizado, com a premissa de Jörn Rüsen (2015b), observando o processo de subjetivação e orientação temporal a partir da presença de valores que fogem da cientificidade e da especificidade normativa.

Intersubjetividade e verdade histórica, e sua articulação com a consciência histórica foram debatidos com profundidade por Fronza (2012). Para não repetilo, eis as ideias centrais do autor:

1) A intersubjetividade emana verdade ao entender que o conhecimento é socialmente transmitido, onde o sujeito é socialmente constituído e constituinte, destarte, a experiência com a totalidade se dá dentro de um sistema de valores de sua coletividade respectiva;

2) A verdade histórica se dá mediante ao processo de confirmação empírica da tese, onde a explicação na narrativa histórica deve ser problematizada de forma que seja possível perceber o local de fala do autor, intencionalidade, perspectividade, e que contribuam para o presente contextualizando em múltiplas causalidades onde as narrativas devem ser vistas como evidências em 
confronto, num ato intersubjetivo entre leitor-autor (historiador - sociedade) e autor-autor (história da historiografia)

3) A reinvindicação de verdade da ciência da história se dá de maneira outra de outros tipos de consciência histórica, em que se percebe a necessidade de validade universal de verdade para o enraizamento do conhecimento histórico na sociedade, porém isso só é alcançado por estratégias comunicativas, as quais sofrerão resistência do público.

Somente pelo entendimento da subjetivação e na oportunidade de racionalização tal qual teorizada na história enquanto ciência que se torna possível à utilização do saber histórico para além da vida prática. A objetividade confronta a subjetividade quando a consciência histórica o obriga a distanciar-se, temporalmente, da experiência humana tida na tradição.

As próprias carências de orientação o obrigam a procurar formas que possibilitem o embate político, intersubjetivo a partir da narrativa histórica, a ressignificar os sedimentos do passado que não mais contemplam tais carências no processo que, antes de construção de identidade deve descontruir a identidade, estranhamento da trajetória de si e de outros, numa ampliação temporal e subjetiva até que finalmente volte-se para a práxis (Rüsen 2015b), e assim como bem observado por Fronza (2012. p. 32):

Acontece, portanto, um confronto intersubjetivo entre a realidade histórica dos sujeitos no presente com o real dos outros sujeitos do passado. Isso pode ampliar, no jovem que aprende historicamente, uma consciência histórica voltada para a construção de projetos de futuros que promovam um sentido de orientação para a necessária superação das carências estruturais da humanidade.

\section{Considerações finais}

Levando em consideração o papel da "subjetivação como fundamento da aprendizagem histórica" e na convicção que a aprendizagem histórica é "um processo fundamental e básico da vida humana prática" (RÜSEN, 2012 p. 73), este trabalho procurou sistematizar leituras sobre a relação de artefatos 
artísticos portadores de discurso histórico, a imanência de verdade provida da cultura histórica e possíveis análises da relação entre sujeito-artefato tomando a intersubjetividade como guia, a partir de investigações que tomam como critério os princípios da cognição histórica situada (SCHMIDT, 2009).

A partir da leitura e diálogo feito com Jörn Rüsen (2015), Marcelo Fronza (2012) e Bodo V. Borries (2016) é possível conclui que: a atribuição de sentido para o passado humano mediante as formatações estéticas, artísticas do saber histórico perpassa a intersubjetividade como principal reduto de subjetivação, da formação da identidade histórica e da participação na cultura histórica. Para as jovens estudantes, o fator estético é articulador de significância da temporalidade e sua plausibilidade está no ato comunicativo, de confronto, onde os impedimentos morais, éticos e religiosos próprios da cultura histórica assumem carga na percepção, trato e julgamento da experiência destes artefatos culturais. A formação histórica tem como função última inserir, através da teoria da história, a controvérsia (pluralidade de sentido) ao se fazer perceber a desnaturalização dos fenômenos humanos e dar posição protagonizante ao sujeito no processo de subjetivação das narrativas de constituição de sentido para a consciência histórica.

\section{Referências}

ALVES, R. C. Aprender História com Sentido para a Vida: consciência histórica em estudantes brasileiros e portugueses. 2011. 322 f. Tese (Doutorado) Faculdade de Educação, Universidade de São Paulo, São Paulo, 2011.

BONETE, W. J.; FREITAS, R. R. Cultura Histórica e Identidade: contribuições conceituais para investigações sobre a formação histórica docente. Revista Labirinto. Porto Velho-RO, Ano XV, v. 22, p. 156-176, 2015

DIVARDIM, T.; SCHMIDT, M. A. Consequências da teoria da narrativa histórica para a didática da história: algumas possibilidades para a práxis dos professores. Revista de Teoria da História. Universidade Federal de Goiás. Ano 6, n. 11, Dez/2014,

FRONZA, M. A Intersubjetividade e a verdade na aprendizagem histórica de jovens estudantes a partir das histórias em quadrinhos. Tese de doutorado, PPGE-UFPR, Curitiba, 2012 
RÜSEN, Jörn. A razão histórica: Teoria da história: os fundamentos da ciência histórica. Brasília: UnB, 2010a.

. História viva: Teoria da História III: formas e funções do conhecimento histórico. Brasília: UnB, 2010b.

Reconstrução do passado: Teoria da História II: os princípios da pesquisa histórica. Brasília: UnB, 2010c.

Aprendizagem Histórica: Fundamentos e Paradigmas. Curitiba: W. A. Editores, 2012

Teoria da História: Uma teoria da história como ciência. Curitiba: W. A. Editores, 2015

SCHMIDT, M. A. Cognição histórica situada: que aprendizagem histórica é essa? In: SCHMIDT, Maria Auxiliadora; BARCA, Isabel (Org.). Aprender História: perspectivas da Educação Histórica. Ijuí: Unijuí, 2009, p. 21-51.

BORRIES. B. Von. O Aprendizado de História como Chance de Participação na Cultura Histórica, Apuração da Identidade Histórica e Prática em Competência Histórica. In: SCHMIDT, M. A.; FRONZA, M.; NECHI, L. P. (Org.). Jovens e Consciência Histórica. Curitiba: W.A. Editores, 2016a

Lidando com Histórias Difíceis. In: SCHMIDT, Maria A.; FRONZA, Marcelo; NECHI, Lucas Pydd (Org.). Jovens e Consciência Histórica. Curitiba: W.A. Editores, 2016b

Quatro Abordagens de "Reconstrução Histórica" por Meio da Aprendizagem Histórica. In: SCHMIDT, Maria A.; FRONZA, Marcelo; NECHI, Lucas Pydd (Org.). Jovens e Consciência Histórica. Curitiba: W.A. Editores, 2016c.

A Compensação histórica dos Estudantes: uma interpretação de um caso singular. IN SCHMIDT, Maria Audiliadora; FRONZA, Marcelo; NECHI, Lucas Pydd (org). Jovens e Consciência Histórica. Curitiba: W.A. Editores, 2016c Multiperspectividade: Pretensão Utópica ou Fundamento Factível da Aprendizagem Histórica na Europac In: SCHMIDT, Maria A.; FRONZA, Marcelo; NECHI, Lucas Pydd (Org.). Jovens e Consciência Histórica. Curitiba: W.A. Editores, 2016d.

WILLIAMS, R. La Larga Revolución. Buenos Aires: Nueva Visión, 2013 